American Journal of Animal and Veterinary Sciences 5 (1): 65-70, 2010

ISSN 1557-4555

(C) 2010 Science Publications

\title{
Exposure of Broiler Chickens to a Weak Electromagnetic Field Reduces the Impact of a Simulated, Commercial Eimeria Infection
}

\author{
${ }^{1}$ M.A. Elmusharaf, ${ }^{2}$ J.J. Cuppen, ${ }^{3}$ H.N.A. Grooten, ${ }^{4}$ H.E. Mohamed, \\ ${ }^{4}$ A. Alhaidary and ${ }^{1,4}$ A.C. Beynen \\ ${ }^{1}$ Department of Nutrition, Faculty of Veterinary Medicine, Utrecht University, The Netherlands \\ ${ }^{2}$ Immunent B.V. Veldhoven, The Netherlands \\ ${ }^{3}$ Feed Innovation Services B.V. Wageningen, The Netherlands \\ ${ }^{4}$ Department of Animal Production, College of Food and Agricultural Sciences, \\ King Saud University, Riyadh, Kingdom of Saudi Arabia
}

\begin{abstract}
Problem statement: In a previous study, the exposure of broiler chickens to a weak Electromagnetic Field (EMF) reduced the severity of a coccidiosis infection. The birds were infected by gavage into the crop which was not representative for the field situation. Approach: The possible anticoccidial activity of EMF was investigated in broiler chickens with a simulated, commercial coccidiosis infection. There was an uninfected and infected group not receiving further treatment. Another uninfected and infected group were subjected to EMF treatment. The infection was induced by adding to the litter a mixture of E. acervulina, E. maxima and E. tenella. EMF treatment lasted for 30 min day $^{-1}$; the field strength within the cages was set to $5 \mu$ Tesla rms. Results: Infection with Eimeria resulted in a transient reduction of growth performance in the control chickens. Exposure to EMF counteracted the effect of infection on growth performance. EMF treatment had no effect on oocyst shedding. In the infected birds exposed to EMF, the lesion scores related to the three Eimeria species were generally lower than in the infected controls. Due to cross-contamination, the uninfected birds also showed intestinal lesions, the severity being less than in the infected chickens. In the uninfected birds, EMF treatment also had reduced the severity of the lesions. Conclusion: In this study EMF exposure protected against coccidiosis in broiler chickens. Consequently, EMF was considered as a possible alternative to anticoccidial drugs.
\end{abstract}

Key words: Electromagnetic fields, natural infection, coccidia, broilers

\section{INTRODUCTION}

Coccidiosis is a common infectious disease in poultry, causing major economic losses. The protozoan parasite of the genus Eimeria multiplies in the intestinal tract of poultry and produces tissue damage, resulting in reduced growth and increased susceptibility to pathogens such as Clostridium perfringens, leading to necrotic enteritis (Maxey and Page, 1977; Shane et al., 1985). The Eimeria species have a complex life cycle that occurs outside the host (exogenous stages) and inside the host (indigenous stages). During the indigenous stage, there are both intracellular and extracellular stages and both asexual and sexual reproduction. The complex life cycle of the Eimeria is associated with complex host immune responses to the parasite (Lillehoj, 1994; Lillehoj and Trout, 1996).
The invasion of the Eimeria sporozoites into the intestinal epithelium results in massive infiltration of macrophages, granulocytes and lymphocytes into the lamina propria. The macrophages modulate the severity of the infection and the lymphocytes, in particular $\mathrm{CD}^{+} \mathrm{T}$ cells, act as inducer of an effective immune response. Both macrophages and lymphocytes are the source of cytokine production in the intestine during Eimeria infection and thereby modulate the immune response (Breed et al., 1997; Lillehoj, 1994; Lillehoj and Trout, 1996). It has been reported that an electromagnetic field (EMF) causes stress at the cellular level, leading to the production of cytokines followed by an enhanced immune response (Simko and Mattsson, 2004). We hypothesized that exposure of broiler chickens to EMF may antagonize the effects of coccidiosis infection. Indeed, in broiler

Corresponding Author: M.A. Elmusharaf, Department of Nutrition, Faculty of Veterinary Medicine, Utrecht University, The Netherlands 
chickens infected with an Eimeria mixture containing E. acervulina, E. maxima and E. tenella, the exposure to EMF was shown to counteract the decrease in weight gain and feed intake as well as the development of intestinal lesions (Elmusharaf et al., 2007).

In our previous study (Elmusharaf et al., 2007) the chickens had been infected with a mixture of Eimeria by a single dose administered through gavage into the crop. Infection through gavage with a single high dose of inoculum has no similarity with the field situation and might result in results with no practical relevance. Standardized infection through the litter mimics the field situation, but can be done under controlled conditions and allows experimental flexibility and a large number of experimental units within the research facility (Elmusharaf et al., 2010).

In the present study, the possible anticoccidial activity of EMF was further investigated. In broiler chickens, a natural progression of coccidial infection was simulated by adding to the litter a mixture of E. acervulina, E. maxima and E. tenella. The effects of EMF exposure on growth performance, intestinal lesions and oocyst excretion were measured.

\section{MATERIALS AND METHODS}

Birds and housing: About 272-one-day-old female broilers (Ross 308) were purchased from a local hatchery. On the day of arrival (day 1), they were wingbanded and randomly housed in wire-floor, suspended cages. Each cage was provided with thick foil and wood shavings as litter. Continuous lighting was provided throughout the experiment. The temperature in the cages on arrival of the birds was $32^{\circ} \mathrm{C}$ and then gradually decreased to $20^{\circ} \mathrm{C}$ at the end experiment.

Diets: Starter and grower diets were used. The diets did not contain growth promoters or coccidiostats. The starter diet was offered until day 13 , followed by the grower diet. The ingredient composition of the diets was as follows $\left(\mathrm{g} \mathrm{kg}^{-1}\right.$ diet as fed; starter/grower): Wheat (250/500), soybean meal (49\% crude protein) (345.5/253.7), corn (27.50/12.29), animal fat (4.00/500), extracted rape seed meal (2.00/3.00), soybean oil (1.87/1.39), corn gluten (1.0522/0.000), premix $(0.50 / 0.50)$, salt $(0.2119 / 0.1902)$, sodium bicarbonate $(0.2367 / 0.2295)$, monocalcium phosphate (1.0995/0.4276), limestone (1.4674/1.0469), DLmethionine $(0.2695 / 0.2146), \quad$ L-lysine $\quad \mathrm{HCl}$ $(0.1723 / 0.2418)$, L-threonine $(0.0638 / 0.0855)$, phytase $(0.0100 / 0.010)$. Throughout the experiment, the birds had free access to feed and tap water.
Experimental design: The experiment had a $2 \times 2$ factorial design with 8 replicates, each replicate consisting of 8 birds. On day 13, the broilers were weighed and divided over the 4 experimental groups so that the weight distributions of the groups were similar. There was an uninfected and infected group not receiving further treatment. Another uninfected and infected group was subjected to EMF treatment, which was started on day one. The infection with a mixture of Eimeria species was done on day 15 (Table 1). Under each cage of the EMF treated birds, there was a magnetic coil, consisting of 50 loops of $1.5 \mathrm{~mm}^{2}$ electricity wire. The coils were connected via a relays bank to an amplifier and signal generator controlled by a microprocessor, which regulated the period of time and the EM field per cage. The EMF treatment period lasted for $30 \mathrm{~min}$ and was given to each cage consecutively and once per $24 \mathrm{~h}$. The field strength within the cages was set to $5 \mu$ Tesla rms, verified by a FW Bell 5180 Tesla meter with a MOS51-3204 Low field probe. In order to avoid any effect of EMF exposure on the other groups, the EMF-free and EMFinfected groups were housed in adjacent rooms within the facility. The cages of the uninfected and infected groups had evenly distributed locations.

Experimental infection procedure: To test the anticoccidial activity of the EMF, a natural simulation of a coccidial infection within the broilers' test facility was developed. This was accomplished by placing both infected groups on day 15 in new litter seeded with sporulated coccidial oocysts. The infected chickens would pick up the oocysts from the seeded litter.

Table 1: Post-infection growth performance for the four experimental

\begin{tabular}{|c|c|c|c|c|c|}
\hline \multirow{2}{*}{$\begin{array}{l}\text { Variable } \\
\text { and } \\
\text { days PI }\end{array}$} & \multicolumn{2}{|c|}{ Control $^{1}$} & \multicolumn{2}{|l|}{ EMF } & \multirow{2}{*}{$\begin{array}{l}\text { Poolec } \\
\text { SEM }\end{array}$} \\
\hline & \multicolumn{2}{|c|}{ Uninfected Infected } & \multicolumn{2}{|c|}{ Uninfected Infected } & \\
\hline \multicolumn{6}{|c|}{ Body weight (g) } \\
\hline Day 6 & $738^{\mathrm{a}}$ & $658^{\mathrm{b}}$ & $690^{\mathrm{b}}$ & $684^{\mathrm{b}}$ & 15.75 \\
\hline Day 13 & $1183^{\mathrm{a}}$ & $1021^{\mathrm{b}}$ & $1191^{\mathrm{a}}$ & $1216^{\mathrm{a}}$ & 25.04 \\
\hline Day 21 & $1644^{\mathrm{a}}$ & $1539^{\mathrm{b}}$ & $1701^{\mathrm{a}}$ & $1686^{\mathrm{a}}$ & 37.31 \\
\hline \multicolumn{6}{|c|}{ Weight gain $\left(\mathrm{g} \mathrm{day}^{-1}\right)$} \\
\hline Days 1-6 & $50^{\mathrm{a}}$ & $45^{\mathrm{b}}$ & $45^{\mathrm{b}}$ & $46^{\mathrm{ab}}$ & 1.54 \\
\hline Days 7-13 & $65^{\mathrm{a}}$ & $56^{\mathrm{b}}$ & $66^{\mathrm{a}}$ & $67^{\mathrm{a}}$ & 2.08 \\
\hline Day 14-21 & 61 & 65 & 67 & 68 & 3.93 \\
\hline \multicolumn{6}{|c|}{ Feed intake $\left(\mathrm{g} \mathrm{day}^{-1}\right)$} \\
\hline Days 1-6 & $85^{\mathrm{a}}$ & $75^{\mathrm{b}}$ & $76^{\mathrm{b}}$ & $76^{\mathrm{b}}$ & 2.20 \\
\hline 13 & $114^{\mathrm{b}}$ & $106^{\mathrm{b}}$ & $116^{\mathrm{a}}$ & $115^{\mathrm{a}}$ & 2.68 \\
\hline Day $14-21$ & 139 & 142 & 141 & 136 & 5.01 \\
\hline \multicolumn{6}{|c|}{ Feed Conversion Ratio (FCR) } \\
\hline Days 1-6 & 1.71 & 1.69 & 1.67 & 1.64 & 0.037 \\
\hline Days 7-13 & 1.77 & $1.91^{\mathrm{b}}$ & 1.76 & $1.72^{\mathrm{a}}$ & 0.050 \\
\hline Days 14-21 & 2.36 & 2.20 & 2.18 & 2.02 & 0.111 \\
\hline
\end{tabular}

a $,{ }^{b},{ }^{c}$ : Mean values within the same row with different superscript letter are significantly different $(\mathrm{p}<0.05)$. Data are presented for 8 cages per experimental group 
The uninfected birds showed intestinal lesions as would be expected based on oocyst shedding (Table 3). However, the severity of the lesions in the uninfected birds was consistently lower than in the infected chickens. Lesion scores due to E. acervulina and E. maxima on days 6 and $21 \mathrm{PI}$ in the infected chickens were significantly lower in EMF-treated animals than in the controls. The lesions caused by E. tenella were less severe on days 13 and 21 PI for the infected EMFtreated chickens versus the infected controls. On days 13 and $21 \mathrm{PI}$, the uninfected chickens exposed to EMF had lower lesion scores than the uninfected controls, but the difference not always reached statistical significance.

\section{DISCUSSION}

It was assumed that the use of litter contaminated with oocysts would simulate a natural coccidiosis infection. Oocyst shedding in the infected birds was found to peak on day 13 PI followed by a decline on day 21 PI. This pattern of oocyst shedding agrees with findings in commercial broiler operations (Peek and Landman, 2003). The presence of oocysts in the excreta of the uninfected chickens indicates that cross contamination had occurred. Although we attempted to prevent cross contamination, we feel that it does not affect the purpose of this study, i.e., studying the effect of EMF exposure on the severity of coccidiosis infection. The lesions in the uninfected chickens were less severe than in the infected ones. It could even be suggested that because of the cross contamination, the effect of EMF at two levels of infection can be evaluated.

Infection with Eimeria resulted in a significant reduction of growth performance in the EMF chickens, which was no longer apparent at the end of the experiment. An initial depression of technical performance followed by compensatory weight gain has been reported in chickens immunized against coccidiosis by hatchery spray (Williams and Andrews, 2001). It was obvious that exposure to EMF counteracted the effect of infection on growth performance (Table 1). In the EMF-treated chickens, the infection did not reduce body weight, weight gain and feed intake and did not raise the feed conversion ratio. The positive effect of EMF on the infected birds in this experiment may extend to laying hens. Keirs et al. (2005) reported that exposure of egglayer flocks to EMF improved production, which may have important welfare and economic implications.

Contrary to growth performance, the number of oocysts in excreta was not significantly influenced by
EMF exposure. This observation may not be surprising. Oocyst shedding only reflects the intensity of the infection at the time of sampling (Hodgson, 1970). Indeed, various workers have reported that oocyst production correlates only poorly with the performance of broiler chickens (Jeffers, 1975; Williams and Catchpole, 2000; Williams and Andrews, 2001). Moreover, Reid (1975) has criticized the use of oocyst shedding as the only index of the anticoccidial activity of drugs because medicated chickens may even produce more oocysts than do un-medicated chickens. If any, in this study, the anticoccidial activity of EMF was associated with a tendency towards diminished excretion of oocysts.

Examination of the intestine on day 6 PI showed that in the infected birds exposed to EMF the lesion scores related to E. acervulina and E. maxima infection were significantly lower than in the infected controls, but the lesions due to the E. tenella were not affected by EMF. On days 13 and $21 \mathrm{PI}$, the group mean lesion scores for all three Eimeria species were lower in infected chickens exposed to EMF than in the infected controls. In the uninfected birds, there was no effect of EMF on intestinal lesions on day 6 PI, but on days 13 and $21 \mathrm{PI}, \mathrm{EMF}$ treatment had significantly reduced the severity of the lesions. Factors that might contribute to the differences in response of E. tenella and E. acervulina and E. maxima to EMF include site of parasite invasion, host immune reaction at the infection site and parasite infective stage (Allen, 1987), Furthermore, E. acervulina and E. maxima are more immunogenic than E. tenella (Rose and Long, 1962). On day $13 \mathrm{PI}$, the lesion scores due to E. acervulina, E. maxima and E. tenella in both infected groups were on average lower than on day 6 PI. The opposite was seen in the uninfected chickens. The lesions on day 13 PI in the infected chickens are secondary lesions induced by re-infection as a consequence of the initial infection (Williams and Andrews, 2001; Williams, 2003). Oocysts that are excreted initially after a coccidiosis infection are less pathogenic than oocysts shed later because the latter have completed their life cycle in the host (Jeffers, 1975; Ryley et al., 1976).

The molecular basis underlying the observed antagonistic activity of EMF on coccidiosis infection in broiler chickens is unknown, but it could relate to one or more of the various biological effects that have been described. EMF exposure may have an antiinflammatory effect (Cronstein et al., 1999; Montesinos et al., 2000; Vallbona and Richard, 1999) and increased blood flow and improved wound healing have been documented (Gessi et al., 2000; Goldin et al., 1981). Possibly, EMF treatment of the 
broiler chickens had resulted in increased peripheral blood flow and massive infiltration of macrophages into the damaged tissue, leading to the observed reduction of coccidial lesions. Jeurissen et al. (1996) reported that in immune chickens, fewer sporozoites will reach the crypt epithelium and the formation of schizonts is inhibited. Sporozoites that had failed to reach the crypt epithelium within $48 \mathrm{~h}$ after infection were detected within or were surrounded by macrophages, indicating that the presence of these cells can moderate the intensity of a primary infection.

\section{CONCLUSION}

In this study EMF exposure reduced the severity of coccidiosis in broiler chickens with a simulated, commercial Eimeria infection. Further study on the effect of EMF on coccidiosis infection is needed. The uninfected birds treated with EMF showed a lower feed intake and weight gain than did the uninfected control birds. Whether or not this observation was caused by a room effect is not known. The control birds and EMFtreated birds had to be housed in different rooms, albeit that they were adjacent. As mentioned above, the mechanism by which EMF exerts its anticoccidial effect is not known. From a practical point of view, it would be relevant to find out whether optimizing the conditions of EMF could increase its anticoccidial activity. Perhaps, EMF exposure could serve as an alternative to the anticoccidial drugs currently used.

\section{REFERENCES}

Allen, P.C., 1987. Physiological responses of chicken gut tissue to coccidial infection: comparative effects of Eimeria acervulina and Eimeria mitis on mucosal mass, carotenoid content and brush border enzyme activity. Poult. Sci., 66: 1306-1315. PMID: 3684853

Breed, D.G., J. Dorrestein, T.P. Schetters, L.V. Waart, E. Rijke and A.N. Vermeulen, 1997. Peripheral blood lymphocytes from Eimeria infected chicken produce gamma-interferon after stimulation in vitro. Parasite Immunol., 19: 127-135. PMID: 9106818

Cronstein, B.N., M.C. Montesinos and G. Weissmann, 1999. Sites of action for future therapy: An adenosine dependent mechanism by which aspirin retains its anti-inflammatory activity in cyclooxygenase-2 and NFkappaB knockout mice. Osteoarthrit. Cartil., 7: 361-363. PMID: 10419767

Elmusharaf, M.A., J.J. Cuppen, H.N.A. Grooten and A.C. Beynen, 2007. Antagonistic effect of electromagnetic field exposure on coccidiosis infection in broiler chickens. Poult. Sci., 86: 2139-2143. PMID: 17878443
Elmusharaf, M.A., H.E. Mohamed, A. Alhaidary and A.C. Beynen, 2010. Efficacy and characteristics of different methods of coccidiosis infection in broiler chickens. Am. J. Anim. Vet. Sci., 5: 45-51.

Gessi, S., K. Varani, S. Merighi, E. Ongini and P.A. Borea, 2000. $\mathrm{A}_{2 \mathrm{~A}}$ adenosine receptors in human peripheral blood cells. Br. J. Pharmacol., 129: 2-11. PMID: 10694196

Goldin, J.H., B.N. Nancarrow and J.D. Marshall, 1981. The effects of Diapulse on the healing of wounds: A double-blind randomized controlled trial in man. Br. J. Plast. Surg., 34: 267-270. PMID: 7023583

Hodgson, J.N., 1970. Coccidiosis: oocyst counting technique for coccidiostat evaluation. Exp. Parasitol., 28: 99-102. PMID: 5459879

Jeffers, T.K., 1975. Attenuation of Eimeria tenella through selection of for precociousness. J. Parasitol., 61: 1083-1090. PMID: 7023583

Jeurissen, S.H.M., E.M. Janse, A.N. Vermeulen and L. Vervelde, 1996. Eimeria tenella infection in chickens: Aspects of host-parasite interaction. Vet. Immunol. Immunopathol., 54: 231-238. PMID: 8988869

Johnson, J. and W.M. Reid, 1970. Anticoccidial drugs: Lesion scoring techniques in battery and floor-pen experiments with chickens. Exp. Parasitol., 28: 30-36. PMID: 5459870

Keirs, R.W., E.D. Peebles, W.J. Sarjeant, P.D. Gerard, and J.D. Terner, 2005. Assessment of the effects of electromagnetic field modification on egg-laying hens in commercial flocks as indicated by production measures. Am. J. Vet. Res., 66: 1425-1429. PMID: 16173488

Lillehoj, H.S., 1994. Analysis of Eimeria acervulinainduced changes in the intestinal $\mathrm{T}$ lymphocytes subpopulations in two chicken strains showing different levels of susceptibility to coccidiosis. Res. Vet. Sci., 56: 1-7. PMID: 7908452

Lillehoj, H.S. and J.M. Trout, 1996. Avian gutassociated lymphoid tissues and intestinal immune responses to Eimeria parasites. Clin. Microbiol. Rev., 9: 349-360. PMID: 8809465

Maxey, B.W. and R.K. Page, 1977. Efficacy of lincomycin feed medication for the control of necrotic enteritis in broiler-type chickens. Poult. Sci., 56: 1909-1913. PMID: 611495

Montesinos, M.C., J.S. Yap, A. Desai, I. Posados, C.T. Mccrary and B.N. Cronstein, 2000. Reversal of the anti-inflammatory effects of methotrexate by the non selective adenosine receptor antagonist theophylline and caffeine: Evidence that the antiinflammatory effects of methotrexate are mediated via multiple adenosine receptors in rat adjuvant arthritis. Arthrit. Rheumatism, 43: 656-663. PMID: 10728760 
Peek, H.W. and W.J.M. Landman, 2003. Resistance to anticoccidial drugs of Dutch avian Eimeria spp. field isolates originating from 1996, 1999 and 2001. Avian Pathol., 32: 391-401. PMID: 17585463

Reid, W.M., 1975: Relative value of oocyst count in evaluating anticoccidial activity. Avian Dis., 19: 802-811. PMID: 1200950

Rose, M.E. and P.L. Long, 1962. Immunity to fours species of Eimeria in fowl. Immunology, 5: 79-92. PMID: 14493839

Ryley, J.F., R. Meade, J. Hazelhurst and T.E. Robinson, 1976. Methods in coccidiosis research: Separation of oocysts from faeces. Parasitology, 73: 311-326. PMID: 13340

Shane, S.M., J.E. Gyimah, K.S. Harrington and T.G. Snider, 1985. Etiology and pathogenesis of necrotic enteritis. Vet. Res. Commun., 9: 269-287. PMID: 2869608

Simko, M. and M. Mattsson, 2004. Extremely low frequency electromagnetic fields as effectors of cellular responses in vitro: Possible immune cell activation. J. Cell. Biochem., 93: 83-92. PMID: 15352165
Vallbona, C. and T. Richard, 1999. Evolution of magnetic therapy from alternative to traditional medicine. Phys. Med. Rehabil. Clin. North Am., 10: 729-754. PMID: 10516987

Williams, R.B. and J. Catchpole, 2000. A new protocol for a challenge test to assess the efficacy of live anticoccidial vaccines in chickens. Vaccine, 18: 1178-1185. PMID: 10649618

Williams, R.B. and S.J. Andrews, 2001. The origin and biological significance of the coccidial lesions that occurs in chickens vaccinated with live attenuated anticoccidial vaccine. Avian Pathol., 30: 215-220. PMID: 19184903

Williams, R.B., 2003. Anticoccidial vaccination: The absence or reduction of numbers of endogenous parasites from gross lesions in immune chickens after virulent coccidial challenge. Avian Pathol., 32: 535-543. PMID: 14522710 